\title{
A Melitofilia em Passiflora alata Dryander (Passifloraceae), em Vegetação de Restinga*
}

\author{
Isabela Galarda Varassin ${ }^{1}$ \\ Ary Gomes da Silva ${ }^{2}$
}

\begin{abstract}
RESUMO
A polinização de Passiflora alata Dryander decorre da atividade de coleta de néctar ou pólen por abelhas Anthophoridae e Apidae de grande porte durante todo o período de floração entre março e setembro. O vôo, possivelmente seguindo rotas de visitas, permite a polinização cruzada, favorecida pela deflexão dos órgãos reprodutivos. Há flores que não apresentam deflexão dos estiletes e podem ser consideradas como funcionalmente masculinas, o que pode interferir na alocação total de recursos para a produção de sementes.

Palavras-chave: Passiflora alata, polinização, melitofilia
\end{abstract}

\begin{abstract}
The pollination of Passiflora alata Dryander is accomplished by Anthophoridae and Apidae large bees when collecting nectar or pollen during the flowering time from march to setember. Forage fligth behavior of trap-line bees possibly allowded cross-pollination what is enhanced by deflection of the reproductive organs. Styles of some flowers may not be deflected and could be considerd as functionally male ones, what may interfer in resource allocation to seedset.

Keywords: Passiflora alata, pollination, mellitophily

\section{INTRODUÇÃO}

A família Passifloraceae apresenta distribuição tropical e subtropical, congregando espécies arbóreas, arbustivas, lianas e herbáceas, sendo que o gênero Passiflora ocorre nas áreas mais quentes da América, com algumas espécies na Ásia e Austrália e uma espécie em Madagascar (Heywood 1993). Reúne cerca de 400 espécies de lianas predominantemente neotropicais (Endress 1994), dentre as quais cerca de 200 ocorrem no Brasil (Semir \& Brown 1975).

A polinização por abelhas, por exemplo, foi descrita para algumas espécies como $P$.

edulis (Corbet \& Willmer 1980; Sazima \& Sazima 1989), e outras como P. foetida (Janzen 1968), P. mooreana (Garcia \& Hoc 1994) e P. pentagona (Varassin \& Silva 1994) e também para $P$. alata em florestas semidecíduas (Koschnitzke \& Sazima 1997).

A reprodução sexuada das espécies deste gênero pode envolver tanto sistemas autocompatíveis, como autoincompatíveis, havendo também casos em que ocorrem variedades de ambos os sistemas reprodutivos dentro de uma mesma espécie (Endress 1994). Desde que haja, então, a necessidade de transferência de pólen entre as flores de diferentes genetas para a produção de sementes, a elucidação dos serviços de polinização torna-se fundamental para a

*Monografia apresentada ao Curso de Especialização em Ecologia e Recursos Naturais. Departamento de Ecologia e Recursos Naturais da Universidade Federal do Espírito Santo. Apoio CNPq-CAPES

${ }^{1}$ Pesquisador - Bolsista CNPq. Museu de Biologia "Prof. Mello Leitão". Rua José Ruschi, 4. Centro. 29.650-000. Santa Teresa, ES. Brasil. e-mail: isabela@npd.ufes.br

${ }^{2}$ Professor Adjunto IV. Faculdade de Farmácia e Bioquímica do Espírito Santo Avenida Cleto Nunes, 433. Centro. 29020 -

560. Vitória, ES. Brasil. e-mail: isoary@zaz.com.br
\end{abstract}


biologia deste grupo.

Assim, o objetivo deste estudo foi determinar se ocorre polinização espontânea e/ou agamospermia em Passiflora alata, e a observação do comportamento dos animais visitantes, com ênfase nos polinizadores, nas planícies quaternárias litorâneas, em vegetação de restinga.

\section{MATERIAIS E MÉTODOS}

\section{A. O Local de Estudo}

O estudo foi desenvolvido no Parque Estadual Paulo Vinha, Guarapari, ES, onde ocorrem populações de Passiflora alata Dryander próximas a Lagoa do Milho (2032'38's e $20^{\circ} 32^{\prime} 48^{\prime}$ 'S e $40^{\circ} 23^{\prime} 45^{\prime \prime} \mathrm{W}$ e $\left.40^{\circ} 23^{\prime} 30^{\prime \prime} \mathrm{W}\right)$. O Parque está situado em uma planície litorânea arenosa (Suguio \& Tessler 1984), originada por depósitos marinhos(Flexor et al. 1984).

A caracterização bioclimática da região foi efetuada segundo Bagnouls \& Gaussen (1964) para dados de temperatura e precipitação fornecidos pela Empresa Capixaba de Pesquisa Agropecuária (EMCAPA).

As excursões ao campo foram feitas nos períodos de floração, semanalmente de março a junho e quinzenalmente de agosto a setembro de 1990.

\section{B. A Biologia da Polinização}

Os eventos florais e a atividade dos animais visitantes foram acompanhados ao longo da antese. A atividade dos animais visitantes foi documentada por observação direta e registro fotográfico.

Os visitantes florais foram coletados com rede entomológica e identificados no Centro de Identificação de Insetos Fitófagos (CIIF), Universidade Federal do Paraná (UFPr).

O material testemunho foi identificado por especialista e está depositado no Herbário da UFPr. As descrições das plantas e das flores foram feitas através de observações no campo, onde foram tomadas as medidas das partes florais. Foram empregadas flores conservadas em álcool etílico 70\% (Johansen 1940). e fotografias para a descrição mais detalhada das flores. A terminologia da morfologia floral seguiu a adotada por Semir \& Brown (1975), Tillett (1988) e Escobar (1994).

As avaliações anatômicas da flor foram feitas em botões em estádio de quatro dias anteriores à antese, fixados em FAA-50 (Jensen 1962), à vácuo por 24 horas, e conservados em álcool etílico 70\% (Johansen 1940). Os botões foram desidratados em série butílica, incluídos em parafina (Johansen 1940) e secionados em micrótomo numa espessura de $10 \mu \mathrm{m}$. As seções obtidas foram coradas pelo dupla coloração com Safranina e Azul de Astra (Gerlach 1984). Fímbrias destes botões foram incluídas em historresina Technovit-7100 (Ruetze \& Schmitt 1983) e secionadas em micrótomo numa espessura de $5 \mu \mathrm{m}$, sendo coradas pelo Azul de Toluidina (Pearse 1961). As avaliações microquímicas foram feitas em botões frescos no mesmo estádio dos fixados, sendo o amido revelado pelo Cloreto de Zinco iodado (Costa 1972) e a as substâncias lipofílicas pelo Negro de Sudan B (Jensen 1962). As preparações obtidas foram analisadas e fotografadas em microscópio fotônico Olympus BMAX-50-IV.

A receptividade do estigma foi indicada pela presença da catalase por peróxido de hidrogênio (Van Fleet 1952). O teste foi feito ao longo da antese, estando os estigmas reflexionados ou não.

A viabilidade polínica foi acompanhada por três dias após a antese, através de testes em azul de nitrotetrazólio (NBT) tamponado em piruvato (Jensen 1962). Os testes eram realizados entre lâmina e lamínula, em intervalos de $24 \mathrm{~h}$, acoplados a um controle negativo, e incubados em câmara úmida à $37^{\circ} \mathrm{C}$ por 35 minutos. A contagem dos grãos viáveis sobre o total de grãos de pólen foi feita em microscópio fotônico.

Flores foram ensacadas na pré-antese 
com sacos de tela de nylon de malha $2,6 \mathrm{~mm}^{2}$ para testar se havia autopolinização espontânea e/ou agamospermia.

\section{RESULTADOS}

Passiflora alata é uma liana herbácea que ocupa desde o estrato herbáceo até o arbóreo, de acordo com a disponibilidade dos suportes sobre os quais ocorre. Suas flores são pendentes e, quando no estrato arbustivo, ficam oclusas na folhagem. Em cada ramo abre-se apenas uma flor por dia ou raramente duas. A antese tem início as 04:30h, momento em que as flores não possuem néctar, e o fechamento das flores ocorre as 14:30h. O perfume adocicado de $P$. alata só é perceptível entre meia a uma hora após a abertura da flor, quando passa a ser intenso. Os estigmas estão receptivos durante toda a antese, estando eles deflexionados ou não.

A flor actinomorfa de $P$. alata (Fig. 1a) é solitária, sustentada por um pedúnculo, do qual parte um único pedicelo. Na inserção do pedicelo no receptáculo (Fig. 1b), os feixes vasculares compõem um anel que já apresenta sinais de separação entre si. Desde a base do nectário (Fig. 1c-d), um grupo de feixes mais externos dirigem-se para a periferia da flor, direcionando-se para vascularização dos verticilos apendiculares que incluem sépalas, pétalas e fímbrias da corona. A flor apresenta cinco sépalas e cinco pétalas livres. A superfície abaxial das sépalas apresenta uma ampla faixa verde. As pétalas têm cor arroxeada assim como a superfície adaxial das sépalas.

A corona reúne todas as estruturas contidas entre as pétalas e os estames, ou seja, duas séries de fímbrias, o opérculo, o anel da câmara nectarífera e o límen. As fímbrias, projeções filiformes adjacentes às pétalas, são rajadas de branco e roxo, carnosas, bastante alongadas, ultrapassando a altura dos estiletes e/ou estigmas e formam uma barreira ao acesso da câmara nectarífera. Cada fímbria apresenta vascularização própria, ( Fig. 1e), composta por numerosos feixes vasculares independentes (Fig. 1f). O aroma floral é produzido nas fímbrias, mas os ensaios microquímicos nas fímbrias de botões florais em pré-antese, não revelaram a presença de reservas na forma de amido ou de lipídeos que permitissem caracterizá-las como osmóforos.

O opérculo é uma estrutura membranácea que se expande em direção ao androginóforo e limita o acesso à câmara nectarífera. Na base da flor, o hipanto forma a câmara nectarífera, dentro da qual uma projeção em sua porção mediana constitui o anel nectarífero. O límen se localiza na porção inicial do androginóforo, ultrapassando o opérculo e, nas suas proximidades também foram observadas gotas de néctar. Uma exploração anatômica da região (Fig. 2 c) revelou que ela apresentava as mesmas terminações vasculares do parênquima do nectário (Fig. 2 a), permeado por traqueídeos e feixes floemáticos, organizados em um anel que circunda cinco traços vasculares independentes que suprem os estames e, mais internamente, um outro anel pentangular que supre o ovário tricarpelar (Fig. 2c).

$\mathrm{Na}$ região logo acima do límen, as terminações em traqueídeos não estão mais presentes, permanecendo os traços vasculares independentes e o anel vascular central (Fig. 2d). O límen, entretanto, não apresentou exudação de gotas de néctar como a detectada no anel nectarífero, mas sua organização interna foi muito similar à região do nectário. As gotas encontradas sobre o límen originaramse do extravasamento da câmara nectarífera. Da base do ovário súpero, partem cinco filetes cujos traços vasculares são independentes desde a base da região do nectário (Fig. 2c-e), e acima do ovário ocorrem três, raramente quatro, estiletes.

No início dos movimentos de abertura da flor as anteras estão introrsas, dispostas verticalmente, e o pólen está disponível. Uma vez a flor aberta, os filetes sofrem deflexão, e as anteras descrevem um movimento de $180^{\circ}$, continuando dispostas verticalmente, mas 
agora com as tecas abrindo-se para fora. Permanecem levemente inclinadas durante a antese. É possível ocorrer autopolinização por ocasião da abertura dos botões. Os estiletes se fletem até que os estigmas adotem posição perpendicular ao androginóforo (Fig. 1). Essa deflexão nem sempre ocorre ou pode se dar em velocidades diferentes em cada flor (Fig. 3a). As pétalas e sépalas fletem-se levemente para cima, e posteriormente descrevem movimento inverso, provocando o fechamento das flores às 14:30h.

Foram observadas 19 espécies de abelhas visitando as flores de P. alata (Tabela 1). As visitas às flores iniciam-se uma hora após sua abertura e terminam uma hora antes de seu fechamento, quando o murchamento faz com que as fímbrias impeçam o acesso à câmara nectarífera. Exceção feita à Apis mellifera scutelata, todas abelhas cobrem longas distâncias em vôo, possivelmente em rotas de visitas.

Os polinizadores das flores de $P$. alata são abelhas de grande porte (Tabela 1). Espécies de menor porte visitam a flor sem efetuar a polinização (Fig. 3b-f). As abelhas podem ser subdivididas em três grupos principais (Tabela 2): o primeiro onde que o vôo é pairado, e abelha muda a posição do corpo dentro da flor, o segundo onde a abordagem da flor é rápida, e a abelha entra e sai da flor mantendo a mesma posição e o terceiro, com apenas Apis mellifera scutelata que tem um comportamento bastante distinto das demais.

Das abelhas que coletam néctar, Xylocopa brasilianorum se destaca por envolver os estigmas e as anteras com as pernas, sendo que a polinização estenotríbica se dá pelo contato dos estigmas com o corpo do inseto, também coberto de pólen liberado pela vibração da musculatura das asas da abelha, onde pode estar a carga de grãos estranhos à flor, expondo o estigma de $P$. alata

Tabela 1. Relação entre as espécies de abelhas, tamanho corporal e a polinização

\begin{tabular}{|c|c|c|c|}
\hline Espécies & Tamanho (mm) & Recurso procurado & Polinizadora \\
\hline \multicolumn{4}{|l|}{ Anthophoridae } \\
\hline Centris analis & 13 & néctar & não \\
\hline Centris derasa & 17 & néctar & $\operatorname{sim}$ \\
\hline Centris flavifrons & 17 & néctar & $\operatorname{sim}$ \\
\hline Centris longimana & 20 & néctar & $\operatorname{sim}$ \\
\hline Centris lutea & 20 & néctar & $\operatorname{sim}$ \\
\hline Centris similis & 20 & néctar & $?$ \\
\hline Centris $\mathrm{sp}_{1}$ & 20 & néctar & $\operatorname{sim}$ \\
\hline Centris $\mathrm{sp}_{2}$ & 15 & néctar & não \\
\hline Epicharis flava & 25 & néctar & $?$ \\
\hline Epicharis sp & 24 & néctar & $?$ \\
\hline Xylocopa brasilianorum & 25 & néctar e pólen & $\operatorname{sim}$ \\
\hline Xylocopa. frontalis & 30 & néctar & $\operatorname{sim}$ \\
\hline Xylocopa ordinaria & 30 & néctar & $\operatorname{sim}$ \\
\hline \multicolumn{4}{|l|}{ Apidae } \\
\hline Eulaema cingulata & 22 & néctar & $\operatorname{sim}$ \\
\hline Eulaema nigrita & 20 & néctar & $\operatorname{sim}$ \\
\hline Eulaema saebrai & 29 & néctar & $\operatorname{sim}$ \\
\hline Euglossa $\mathrm{sp}_{1}$ & 15 & néctar & não \\
\hline Euglossa $\mathrm{sp}_{2}$ & 12 & néctar & não \\
\hline Apis mellifera scutelata & 12 & pólen & não \\
\hline
\end{tabular}


Tabela 2. Comportamento das abelhas visitantes e horário de visitação

\begin{tabular}{|c|c|c|c|}
\hline Espécies & Tamanho (mm) & Recurso procurado & Polinizadora \\
\hline \multicolumn{4}{|l|}{ Anthophoridae } \\
\hline Centris analis & 13 & néctar & não \\
\hline Centris derasa & 17 & néctar & $\operatorname{sim}$ \\
\hline Centris flavifrons & 17 & néctar & $\operatorname{sim}$ \\
\hline Centris longimana & 20 & néctar & $\operatorname{sim}$ \\
\hline Centris lutea & 20 & néctar & $\operatorname{sim}$ \\
\hline Centris similis & 20 & néctar & $?$ \\
\hline Centris $\mathrm{sp}_{1}$ & 20 & néctar & $\operatorname{sim}$ \\
\hline Centris $\mathrm{sp}_{2}$ & 15 & néctar & não \\
\hline Epicharis flava & 25 & néctar & $?$ \\
\hline Epicharis sp & 24 & néctar & $?$ \\
\hline Xylocopa brasilianorum & 25 & néctar e pólen & $\operatorname{sim}$ \\
\hline Xylocopa. frontalis & 30 & néctar & $\operatorname{sim}$ \\
\hline Xylocopa ordinaria & 30 & néctar & $\operatorname{sim}$ \\
\hline \multicolumn{4}{|l|}{ Apidae } \\
\hline Eulaema cingulata & 22 & néctar & $\operatorname{sim}$ \\
\hline Eulaema nigrita & 20 & néctar & $\operatorname{sim}$ \\
\hline Eulaema saebrai & 29 & néctar & $\operatorname{sim}$ \\
\hline Euglossa $\mathrm{sp}_{1}$ & 15 & néctar & não \\
\hline Euglossa $\mathrm{sp}_{2}$ & 12 & néctar & não \\
\hline Apis mellifera scutelata & 12 & pólen & não \\
\hline
\end{tabular}

Tabela 3. Viabilidade polínica de $P$. alata pelo teste do NBT em tampão piruvato

\begin{tabular}{cccc}
\hline $\begin{array}{c}\text { Tempo após abertura da } \\
\text { flor (h) }\end{array}$ & $\begin{array}{c}\text { Número de grãos de pólen } \\
\text { viáveis }\end{array}$ & Total & Pólen viável (\%) \\
\hline & & & \\
0 & 248 & 312 & 79,49 \\
24 & 446 & 618 & 72,17 \\
48 & 358 & 399 & 89,72 \\
\hline
\end{tabular}

Total Pólen viável (\%) 
a pólen endógeno e exógeno.

Três espécies de abelhas não foram enquadradas em nenhum grupo pois visitaram P. alata em baixa frequiência, e delas se têm poucas informações. São elas: Centris similis e Epicharis flava (Anthophoridae), que foram observadas em flores altas, após 09:30h da manhã, e Epicharis sp. Além delas, outras quatro espécies, duas de Euglossa e outras duas de Centris (Fig. 3b) possuem corpo de dimensões tais que não as permite participar diretamente do fluxo de pólen.

Foi observado que o beija-flor Eupetomena macroura (Trochilidae) localiza as flores de $P$. alata que ocupam o estrato arbóreo, sem, contudo, coletar néctar.

A posição que as anteras de $P$. alata ocupam durante parte do período de antese é que permite a deposição de grãos de pólen nas abelhas. Assim também, a deflexão dos estiletes posiciona os estigmas de tal maneira que possam receber os grãos de pólen do corpo dos visitantes (Fig. 2).

As flores destas espécies estão receptivas durante toda a antese estando os estigmas flexionados ou não. Apesar de ocorrer transferência de pólen para os estigmas sem a mediação de um vetor de pólen, as flores ensacadas $(\mathrm{n}=27)$ não produziram frutos $(\mathrm{n}=$ 0 ) indicando que $P$. alata não é autocompatível e nem agamospérmica.

Nesta espécie, os grãos de pólen mantêm-se viáveis por pelo menos três dias (Tabela 3).

\section{DISCUSSÃO}

A espécie em estudo teve o material típico coleta por Dombey no Peru (Cervi, 1981), havendo também referências de Masters (1872) e Janzen (1968) para outras florestas tropicais.

A população em estudo, no entanto, foi observada em faixa de planície arenosa litorânea, em vegetação de Restinga. Mantém características peculiares de P. alata var brasiliana Masters, apresentando dois nectários peciolares e dimensões características, conforme descrito por Silva \& Gallo (1984).

Cervi (1981) invalidou taxonomicamente as variedades $P$. alata var brasiliana e $P$. alata var latifolia, ambas de Masters (1872), reduzindo-as à sinonímia de $P$. alata. Cabe salientar, entretanto, que Silva \& Gallo (1984) assinalam para a faixa costeira do Espírito Santo, tanto nas formações de mata como nas de vegetação em mosaico, populações com características de $P$. alata var brasiliana. A outra variedade, caracterizada por possuir proporções de dimensões duas a três vezes maiores no eixo vegetativo e das flores, bem como quatro nectários peciolares, tem distribuição limitada às florestas de Tabuleiro e de Encosta.

P. alata apresenta uma florada extensa, distribuída entre março e setembro, o que corresponde ao período de temperaturas mais baixas, dias com menor fotoperíodo e abrange o período subseco do ano. Foi observado que no início e fim do período de florada há menor número de visitantes florais, o que deve tender a reduzir os fenodesviantes daquela população de $P$. alata. A sobreposição de floradas na população, no entanto, deve garantir amplo fluxo de pólen e manutenção da diversidade genética. A longa viabilidade do pólen favorece ainda seu amplo fluxo intrapopulacional, sendo a polinização cruzada favorecida pela possível autoincompatibilidade da espécie e pela característica de vôo dos visitantes.

$\mathrm{O}$ néctar, recurso alimentar procurado pela quase totalidade das abelhas, é exudado apenas pelo anel da câmara nectarífera, não havendo participação do límen. A proximidade do límen (Fig. 1c) com a câmara nectarífera (Fig. 2a-c) talvez explique a semelhança anatômica das duas regiões, uma vez que em algumas espécies de Passiflora o límen localiza-se abaixo do opérculo, na base do androginóforo, sendo contíguo ao nectário (Silva \& Gallo 1984).

A polinização cruzada é efetuada por abelhas de grande porte (Fig. 3c-e). A 
polinização está relacionada à mudança de posição dos órgãos reprodutivos durante parte da antese, o que é comum no gênero Passiflora (Janzen 1968; Sazima \& Sazima 1978; Endress 1994). A posição inclinada das anteras favorece a deposição de pólen no dorso das abelhas de grande porte, como algumas espécies de Centris e as espécies de Eulaema e Xylocopa (Fig. 2e). A polinização nototríbica pelo pólen do dorso destas abelhas ocorre apenas em estigmas de flores que possuem os estiletes flexionados.

Flores que não apresentam deslocamento dos estiletes (Fig. 2a) podem ser consideradas funcionalmente masculinas, assim como ocorre em P. foetida (Gottsberger et al. 1988), $P$. quadrangularis e $P$. pinnatistipula (Knuth 1904 apud Gottsberger et al. 1988). Observando os mesmos eventos em $P$. incarnata, MAY \& SPEARS (1988) sugerem que ocorra andromonoecia funcional que participaria como um mecanismo modulador de alocação de recursos para produção de sementes.

Apesar de Janzen (1968) basear-se na deflexão do estigma de quatro espécies de Passiflora, incluída P. alata, para determinar o início da receptividade, foi observado que em $P$. alata este fenômeno independe do seu grau de deflexão, podendo o estigma estar receptivo estando os estiletes fletidos ou não. A movimentação dos órgãos reprodutivos estabelece uma barreira temporal para a polinização em estigmas receptivos, mas não uma barreira fisiológica, pois o pólen está disponível durante toda a antese, e os estigmas estão receptivos. Assim, no início da antese, as flores funcionam como doadoras de pólen, e só posteriormente também são funcionalmente femininas.

Como em $P$. alata as fímbrias são bastante desenvolvidas, as abelhas têm necessariamente que se posicionar entre elas e o androginóforo para terem acesso à câmara nectarífera (Fig. 2). Exceção feita a Eulaema seabrai e Xylocopa frontalis que podem permanecer sobre a face externa das fímbrias para coletar néctar. $\mathrm{O}$ fato das fímbrias serem bastante desenvolvidas e carnosas associado com a presença de um androginóforo, deve impedir o acesso à câmara nectarífera pelo beija-flor Eupetomena macroura, pois ele localiza as flores mas não foi visto coletando néctar.

O comportamento dos insetos tem influência direta no fluxo polínico. As abelhas coletoras de néctar, ao entrar e sair da flor, recebem pólen no seu dorso. Se de fato as abelhas empregam vôo em rotas de visitas, exceção feita a A. mellifera scutellata, este comportamento deve favorecer a polinização cruzada de $P$. alata apesar de sua baixa densidade populacional (Janzen 1968).

Apesar do número elevado de espécies de abelhas que visitam as flores de P. alata, a competição interespecífica pelo recurso alimentar pode ser afrouxada por um período de florada extenso (Janzen 1968) como ocorre em P. alata, e pelo deslocamento dos horários de visitação pelas abelhas coletoras de néctar. É possível que as espécies que pairam frente à flor sem visitá-las, como algumas espécies de Centris em P. alata, tenham marcado as flores com feromônios, e só as visitam após a evaporação destes, como ocorre com Xylocopa mordax em flores de Passiflora edulis (Corbet \& Willmer 1980).

Euglossa spp. e Centris spp. (Fig. 3b) possuem corpo de dimensões tais que não as permite participar diretamente do fluxo de pólen, no entanto, talvez possam participar indiretamente, uma vez que, ao promover a redução do volume de néctar, podem elevar a frequiência de visitas das abelhas de grande porte a flores disponíveis na população, assim como postulado por HeiNrich \& Raven (1972) para flores com grande secreção de néctar, com ocorre em $P$. alata (dados não publicados).

No gênero Passiflora, a adaptação à quiropterofilia envolve o horário noturno de abertura, a posição ereta da flor, com sépalas e pétalas fletidas para baixo, a presença de um opérculo filamentoso e uma redução evidente no tamanho dos filamentos da corona. 
Esta redução permite o fácil acesso à câmara nectarífera e a exposição dos órgãos reprodutivos (Sazima \& Sazima 1978). O deslocamento zigomórfico dos órgãos reprodutivos parece ser bem adaptado à polinização por morcegos visto que estes animais têm menor agilidade em manobrar que abelhas e beija-flores (Sazima \& Sazima 1978).

Em três espécies adaptadas à polinização por beija-flores, a flor também é ereta, sépalas e pétalas estão fletidas para baixo e a corona é bastante reduzida (Janzen 1968, Sigrist 1991,Varassin 1996).

A presença de opérculo membranoso parece impedir que beija-flores e morcegos atinjam a câmara nectarífera (Sazima \& Sazima 1978), mas se adequa à coleta de néctar por abelhas devido ao seu flexível aparelho bucal (Koschnitzke \& Sazima 1997). Em $P$. pentagona, no entanto, a presença de opérculo membranoso não limita a coleta de néctar por beija-flores (Silva \& Varassin dados não publicados), indicando que é possível que este caráter seja mais importante para morcegos.

A flor de $P$. alata restringe a visitação por beija-flores e morcegos, considerando que a flor é pendente e a corona muito longa, formando uma barreira de acesso à câmara. $\mathrm{O}$ pequeno espaço deixado entre as fímbrias e o androginóforo não permitiria a coleta de néctar por beija-flores e morcegos na flor actinomórfica de $P$. alata, enquanto que o opérculo membranoso dificultaria ainda mais o acesso à câmara por morcegos.

\section{CONCLUSÕES}

- Passiflora alata parece ser uma espécie auto-incompatível, sendo a polinização cruzada é mediada por abelhas de grande porte;

- Apesar do grande número de abelhas visitantes, é possível que a competição interespecífica seja reduzida pela extensão da florada e pela variação nos horários de visitação;

- A polinização está relacionada com a deflexão dos órgãos reprodutivos;

- A receptividade do estigma não está relacionada com a deflexão dos estiletes. A movimentação dos órgãos reprodutivos estabelece uma barreira temporal para a polinização, mas não uma barreira fisiológica;

- Apesar da flor ser hermafrodita, existem

flores que não apresentam deflexão dos estiletes e podem ser consideradas funcionalmente masculinas.

\section{REFERÊNCIAS BIBLIOGRÁFICAS}

Bagnouls, F. \& Gaussen, H. 1964. Os climas tropicais e sua classificação. Boletim Geográfico 176: 545-566.

Cervi, A. C. 1981. Revisão do gênero Passiflora L. (Passifloraceae) do Estado do Paraná - Brasil. Tese (Doutorado). 241p. Barcelona: Universidade de Barcelona.

Costa, A. F. 1972. Farmacognosia: farmacognosia experimental. Lisboa, Fundação Calouste Gilbenkian. v. 3. 850p.

Corbet, S. A. \& Willmer, P. G. 1980. Pollination of the yellow passionfruit: nectar, pollen, and carpenter bees. Journal of Agriculture Science 95(3): 655-666.

Endress, P. K. Diversity and evolutionary biology of tropical flowers. Cambridge: Cambridge University Press, 1994. 511p.

Escobar, L. K. 1994. Two new species and a key to Passiflora subg. Astrophea. Systematic Botany 19(2): 203-210.

Flexor, J., Suguio, K. \& Martin, L. 1984. Gênese dos cordões litorâneos da parte central da costa Brasileira. In: Simpósio sobre Restingas Brasileiras, Niterói. Anais ... Niterói: CEUFF, Universidade Federal Fluminense. p. 35-45.

Frankie, G. W., Haber, W. A., Opler, P. A. \& Bawa, K. S. 1983. Characteristics and organization of the large bee pollination system in the Costa Rican dry forest. In: Jones, C. E. \& Little, R. J. (eds) 
Handbook of experimental pollination biology. New York. Scientific and Academic Editions. p. 411-447.

Garcia, M. T. A. \& Hoc, P. 1994. Aspectos da biologia floral de Passiflora mooreana (Passifloraceae). In: IV Congresso Latino-Americano de Botânica, Mar del Plata. Resumos ... Mar del Plata. 807 p.

Gerlach, D. 1984. Botanische mikrotechnik. Stuttgart, Georg. Thieme Verlag.

Gottsberger, G., Camargo., J. M. F. \& Silberbauer-Gottsberger, I. 1988. A beepollinated tropical community: the beach dune vegetation of Ilha de São Luiz, Maranhão, Brazil. Botanische Jahrbücher Systematisches 109(4): 469-500.

Heinrich, B. \& Raven, P. H. 1972. Energetics and pollination ecology. Science 176: 597602.

Heywood, V. H. 1994. Flowering plants of the world. London, $\mathrm{B}$. T. Batsford Ltd. $335 \mathrm{p}$.

Janzen, D. H. 1968. Reproductive behavior in the Passifloraceae and some of its pollinators in Central America. Behavior 32: 33-48.

Jensen, W. A. 1962. Botanical hystochemistry; principals and practice. San Francisco. Freeman, W. H. p. 329-355: Enzymes: microscope hystochemistry.

Johansen, D. A. 1940. Plant microtechnique. New York, Mc GrawHill. 523 p.

Killip, E. P. 1938. The American species of Passifloraceae. Field Museum of Natural History. 613 p. v.1 (Botanical Series19).

Koschnitzke, C. \& Sazima, M. 1997. Biologia floral de cinco espécies de Passiflora L. (Passifloraceae) em mata semidecídua. Revista Brasileira de Botânica 20(2): 119-126.

Masters, M. T. 1872. Passifloraceae. In: Martius, C. F. P. von. Flora Brasiliensis... Mônaco, R. Oldenbourg. v.13, part 1, p. 530-628.
May, P. G. \& Spears, E. E. Jr. Andromonoecy and variation in phenotypic gender of Passiflora incarnata (Passifloraceae). American Journal of Botany, New York, v.75, n. 12, p. 1830-1841. dez. 1988

Oliveira, P. E. A. M. de \& Sazima, M. 1990. Pollination biology of two species of Kielmeyera (Guttiferae) from brazilian Cerrado vegetation. Plant Systematics and Evolution 172(1-4): 35-49.

Pearse, A. G. E. 1961. Histochemistry: theoretical and applied. 2 ed. London, J. \& A. Churchill.

Ruetze, M. \& Schmitt, U. 1986. Glykolmethacrykat (GMA) als Einbettungssytem in histologische Untersuchungen von Koniferen-Nadeln. European Journal of Foret Pathology. 16: 321-324.

Sazima, I. \& Sazima, M. 1989. Mamangavas e irapuás (Hymenoptera, Apoidea): visitas, interações e conseqüências para a polinização do maracujá (Passifloraceae). Revista Brasileira de Entomologia 33:(1) 109-118.

Sazima, M. \& Sazima, I. 1978. Bat-pollination of the passion flower, Passiflora mucronata, in Southeastern Brazil. Biotropica 10(2): 100-109.

Semir, J. \& Brown, K. S. Jr. 1975. Maracujá: a flor da paixão. Revista Geográfica Universal 2: 40-47.

Sigrist, R. 1991. Biologia da polinização de Passiflora speciosa (Passifloraceae) em uma mata estacional decídua do ES. In: Congresso de Botânica, Goiânia. Resumos... Goiânia: Universidade Federal de Goiás. 463 p.

Silva, A. G. \& Gallo, M. B. C. 1984. Contribuição ao conhecimento de espécies de Passiflora Linn. das Restingas do Estado do Espírito Santo. h Simpósio sobre Restingas Brasileiras, Niterói. Anais ... Niterói: CEUFF, Universidade Federal Fluminense. p. 233-240.

Suguio, K. \& Tessler, M. G. 1984. Planícies 
de cordões litorâneos quaternários do Brasil: origem e nomenclatura. In: Simpósio sobre Restingas Brasileiras, Niterói. Anais ... Niterói: CEUFF, Universidade Federal Fluminense. p. 1525.

Tillett, S. 1988. S. Passionis passifloris II. Terminologia. Ernestia 48: 1-40.

Varassin, I. G. \& Silva, A. G. 1994. Biologia da polinização de $P$. cf. rhamnifolia (Passifloraceae). In: $46^{a}$ Reunião Anual da Sociedade Brasileira para o Progresso da Ciência, itória. Anais ... Vitória, Universidade Federal do Espírito Santo. 820 p.

Varassin, I. G. 1996. Forrageamento de Phaethornis superciliosus em flores de Passiflora coccinea. In: V Congresso Brasileiro de Ornitologia, Campinas. Resumos ... Campinas: Universidade Estadual de Campinas. 123 p. 


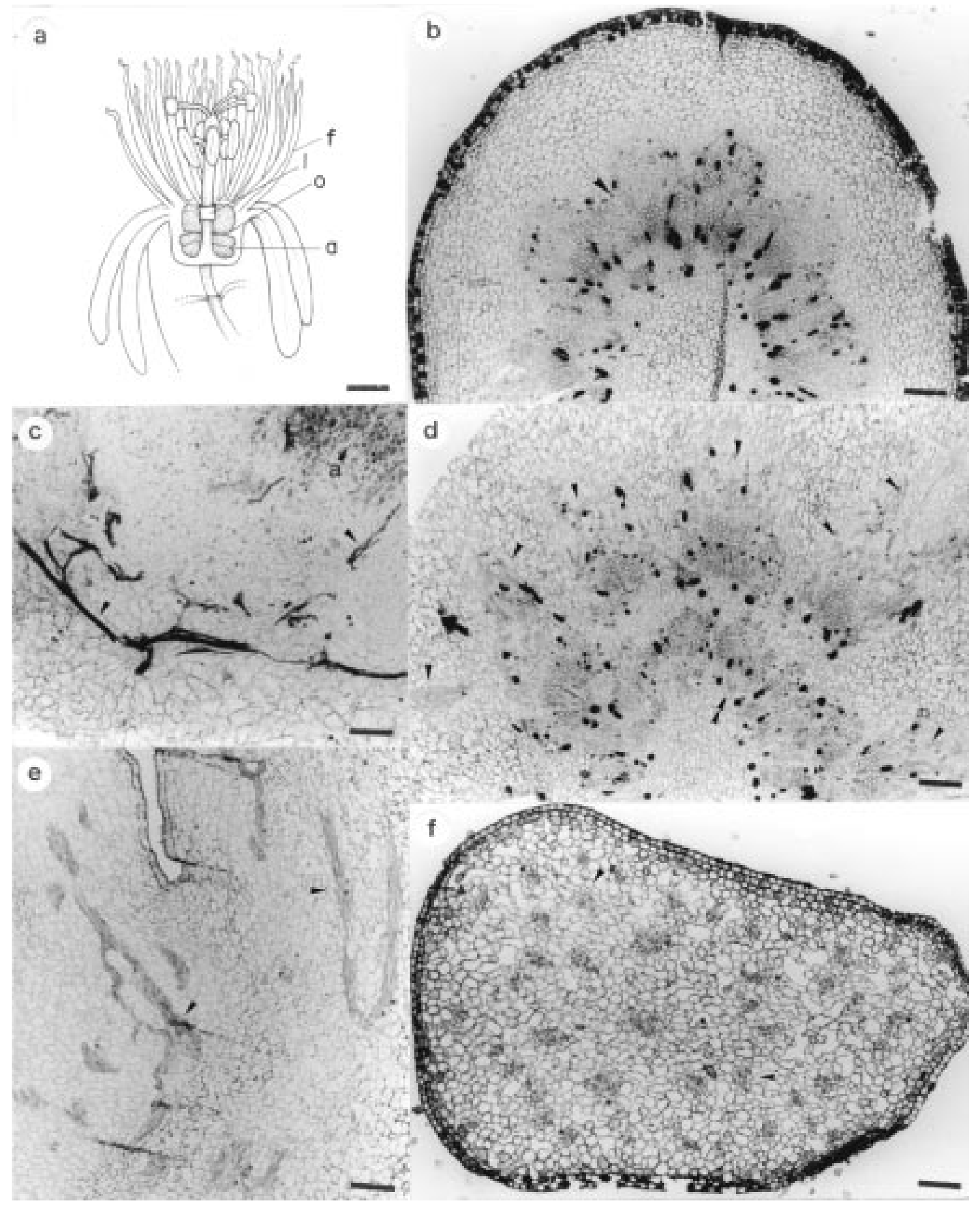

Figura 1. Passiflora alata. Flor. a. Aspecto em corte longitudinal (barra $=10 \mathrm{~mm}$ ), mostrando o anel da câmara nectarífera (a), fímbrias (f), límen (1), opérculo (o). Botão em pré-antese (todas as barras $=150 \mu \mathrm{m}$ ). b. Seção longitudinal da inserção do pedicelo no receptáculo, mostrando o anel vascular (seta) com sinais do início da separação dos feixes; c. Seção longitunidal da base do receptáculo floral, mostrando o parte do parênquima adjacente ao nectário com os traços vasculares (seta) evidenciados; d. Seção transversal da base do receptáculo floral, mostrando a separação dos traços vasculares (seta); e: Seção longitudinal da base das fímbrias, mostrando sua vascularização individualizada (seta;f: Seção transversal de uma fímbria, com seu numerosos traços vasculares independentes (seta). 


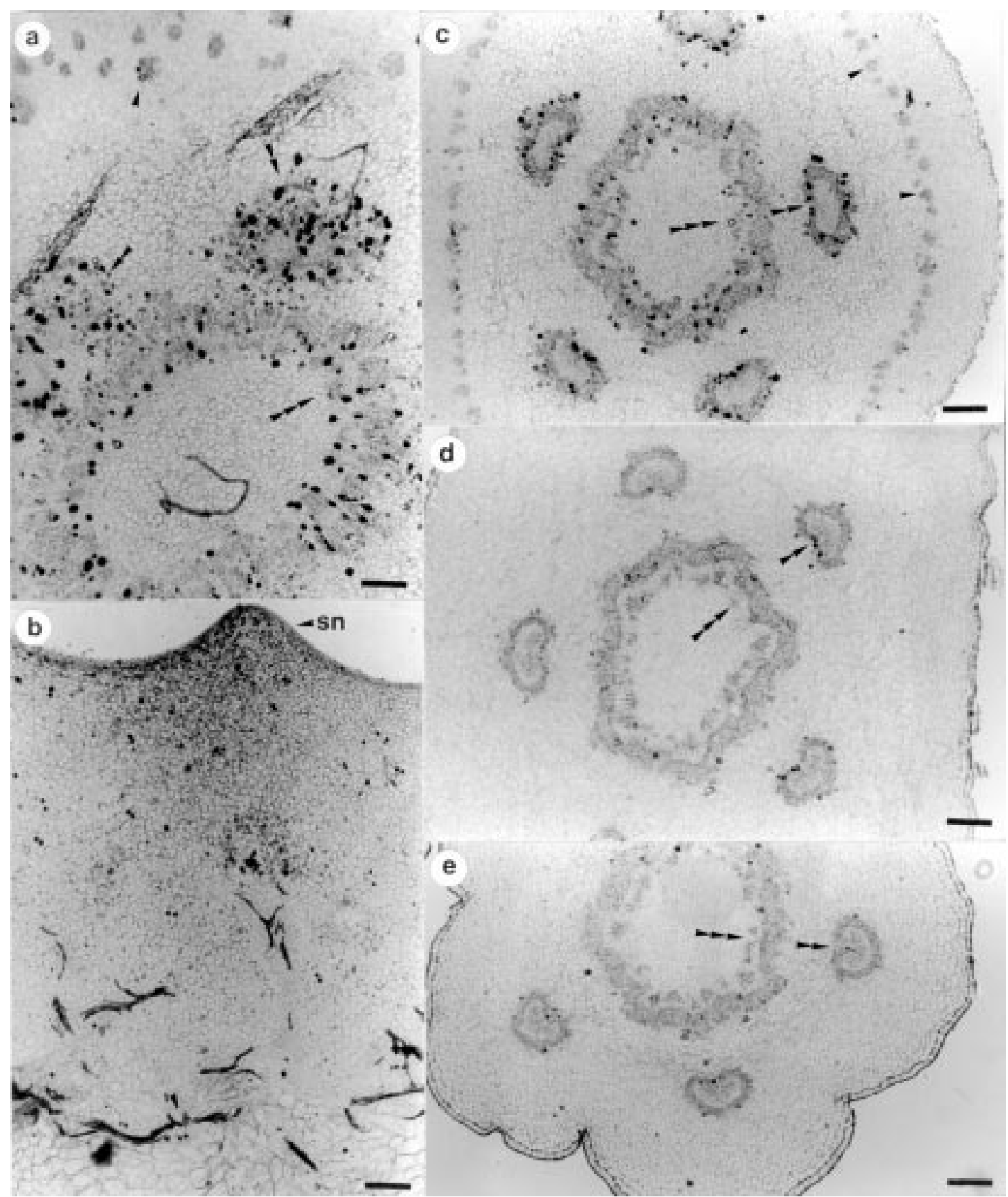

Figura 2. Passiflora alata . Botão em pré-antese (Todas as barras $=150 \mu \mathrm{m})$ a. Seção longitudinal da base do androginóforo; b. Seção longitudinal da câmara nectarífera mostrando o parênquima associado ao anel nectarífero (sn) e sua vascularização; Seção transversal do androginóforo: c. imediatamente abaixo do límen; d. imediatamente acima do límen e e. acima do límen, no ponto de inserção dos filetes, , evidenciando os feixes vasculares do límen (seta), os traços vasculares dos estames (dupla seta) e o anel vascular que supre o ovário (tripla seta). 


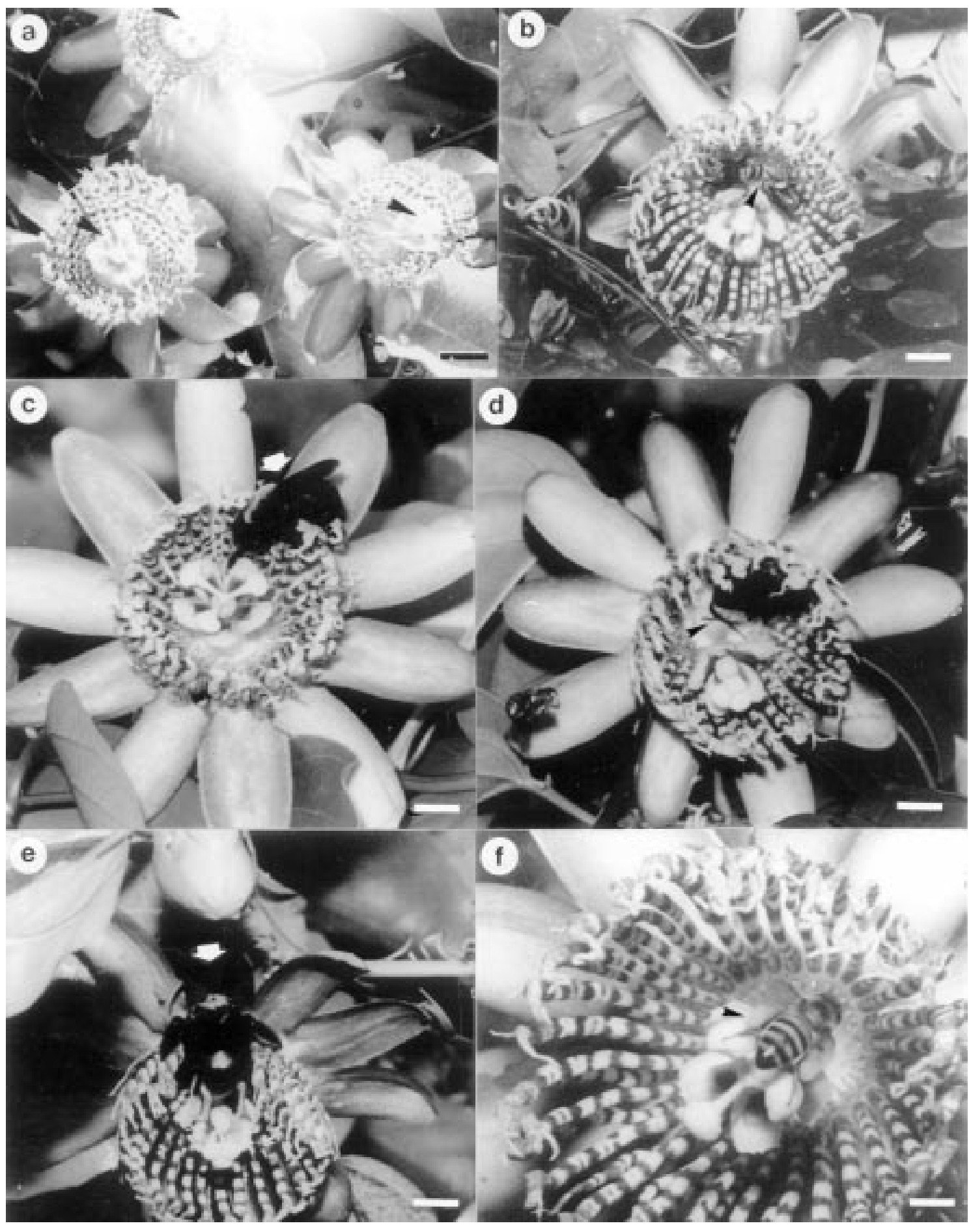

Figura 3. Passiflora alata. Flor em visitação. a. Deflexão diferenciada dos estiletes (seta) de flores de uma mesma idade, no mesmo período do dia (barra $=15 \mathrm{~mm}$ ). Visitantes florais: b. Euglossa sp $_{1}$ (barra $\left.=10 \mathrm{~mm}\right)$, cujo tamanho não permite o contato com os órgãos reprodutivos; c. Centris lutea passando entre as fímbrias para atingir a câmara nectarífera (barra $=10 \mathrm{~mm}) ; \mathbf{d}$. $C$. lutea deslocando o androginóforo (seta) com a cabeça para coletar néctar (barra $=15 \mathrm{~mm})$, $\mathbf{e}$. Xylocopa ordinaria após a coleta de néctar (barra $=15 \mathrm{~mm}$ ), com o dorso carregado de grãos de pólen; $\mathbf{f}$. Apis mellifera scutellata em coleta ativa de pólen, pousada sobre os estigmas (barra $=8 \mathrm{~mm}$ ). 
